\title{
Evaluation of Responsivity to Drought Stress Using Infrared Thermography and Chlorophyll Fluorescence in Potted Clones of Cryptomeria japonica
}

\author{
Yuya Takashima ${ }^{1, *} \mathbb{\infty}$, Yuichiro Hiraoka ${ }^{2}$, Michinari Matsushita ${ }^{1}$ and Makoto Takahashi ${ }^{1}$ \\ 1 Forest Tree Breeding Center, Forestry and Forest Products Research Institute, \\ Forest Research and Management Organization, 3809-1 Ishi, Juo, Hitachi 319-1301, Ibaraki, Japan; \\ matsushita@affrc.go.jp (M.M.); makotot@affrc.go.jp (M.T.) \\ 2 Faculty of Production and Environmental Management, Shizuoka Professional University of Agriculture, \\ 678-1 Tomigaoka, Iwata 438-8577, Shizuoka, Japan; hiraoka.yuichiro@spua.ac.jp \\ * Correspondence: ytakashima@ffpri.affrc.go.jp
}

check for updates

Citation: Takashima, Y.; Hiraoka, Y.; Matsushita, M.; Takahashi, M.

Evaluation of Responsivity to Drought Stress Using Infrared

Thermography and Chlorophyll Fluorescence in Potted Clones of Cryptomeria japonica. Forests 2021, 12, 55. https://doi.org/10.3390/ f12010055

Received: 13 November 2020 Accepted: 30 December 2020 Published: 2 January 2021

Publisher's Note: MDPI stays neutral with regard to jurisdictional clai$\mathrm{ms}$ in published maps and institutional affiliations.

Copyright: $\odot 2021$ by the authors. Licensee MDPI, Basel, Switzerland. This article is an open access article distributed under the terms and conditions of the Creative Commons Attribution (CC BY) license (https:// creativecommons.org/licenses/by/ $4.0 /)$.

\begin{abstract}
As climate change progresses, the breeding of drought-tolerant forest trees is necessary. Breeding drought-tolerant trees requires screening for drought stress using a large number of individuals and a high-throughput phenotyping method. The aim of this study was therefore to establish high-throughput methods for evaluating the clonal stress responses to drought stress using infrared thermography and chlorophyll fluorescence methods in Cryptomeria japonica. The stomatal conductance index $(\mathrm{Ig})$, maximum photochemical quantum yield of photosystem II $(\mathrm{Fv} / \mathrm{Fm})$, and axial growth of four plus-tree clones of $C$. japonica planted in pots were measured weekly for 85 days after irrigation was stopped. The phenotypic trait responsivity to drought stress was estimated by a nonlinear mixed model and by introducing the cumulative water index, which considers the past history of the soil water environment. These methods and procedures enabled us to evaluate the clonal stress responses in C. japonica and could be applied to large-scale clone materials to promote the breeding program for drought tolerance.
\end{abstract}

Keywords: infrared thermography; chlorophyll fluorescence; cumulative drought stress; highthroughput phenotyping; Cryptomeria japonica

\section{Introduction}

The frequency of extreme climatic events, such as droughts and heatwaves, is expected to increase as the global climate change progresses [1]. Higher temperatures and more frequent, longer droughts are expected in Japan [2]. Stress due to drought and high temperatures would have a negative impact on the growth and survival of forest trees $[3,4]$. In particular, drought stress would impair the physiological mechanisms of forest trees, which are dependent on water [5]. Thus, to adapt to these emerging circumstances, drought tolerance has become an important target trait in tree breeding and genetic improvement [6,7].

Breeding for drought resistance has been assessed based on sustained growth or yield or suppressed mortality under water-deficient conditions in crop plants, such as rice [8], wheat [9], and soybeans [10], as in forest trees such as Pinus pinaster [11] and Eucalyptus globulus [12]. When breeding for drought resistance, morphological traits, such as growth, yield, and mortality, and physiological traits, such as water use efficiency (WUE), stomatal conductance, cavitation of conductive tissue, photosynthetic ability, leaf wilting, leaf water potential, and osmotic regulation, are used as target traits. However, most of these traits require considerable effort and time to measure and are thus not suitable for large-scale screening in breeding programs.

Among the physiological traits involved in the drought stress response of plants, leaf transpiration depending on stomatal conductance and photosynthetic ability can be evaluated with high-throughput by using infrared thermography and chlorophyll fluorescence 
methods, respectively [13]. In trees under drought stress, stomatal conductance, which is affected by the transpiration rate, is changed so as to maintain optimal water conditions within trees [14-16]. In addition, the leaf temperature also changes due to evaporative heat loss, which changes with transpiration. A method for estimating stomatal conductance by measuring the change in leaf temperature using infrared thermography has been developed $[13,17]$. Infrared thermography has been applied to some tree species to evaluate drought stress responses, because it enables to obtain data from single leaves, as well as tree crowns, expeditiously (Jatropha curcas [18], Pinus sylvestris [19], Firmiana platanifolia [20], and Vitis vinifera [21]). Chlorophyll fluorescence is another method that has been widely used for to measure photosynthesis [22]. Chlorophyll fluorescence occurs when light energy is absorbed by the chlorophyll antenna but is not used for photosynthesis or converted into heat and which is then re-emitted as red fluorescence. Chlorophyll fluorescence is closely related to photosynthetic carbon metabolism and leaf gas exchange [23,24]. In plants, drought stress increases the water deficit and progressively decreases the carbon assimilation by photosynthesis as a result of both stomatal and metabolic limitations [25-29]. Consequently, the measurement of chlorophyll fluorescence, which is noninvasive, can be used to infer plant viability and performance in response to drought stress [30]. The measurement of stomatal conductance using infrared thermography and the measurement of photosynthesis using chlorophyll fluorescence are thus potentially useful tools for preforming high-throughput phenotyping in tree breeding experiments focused on improving drought resistance.

For plants, soil drought is typically not a transient stress but a cumulative one that is also influenced by past conditions. It is therefore considered that the drought stress responses in plants can be better understood by introducing a cumulative water index. In forest ecology, forest remote sensing, and dendrochronology, the Standardized Precipitation Evapotranspiration Index (SPEI) is used to estimate how the "cumulative stress" associated with drought stress affects the decline and recovery of tree growth in the field [31,32]. However, few reports have examined the relationship between tree responses and cumulative stress under artificially controlled soil water conditions in potted plants. When examining the drought stress responses in potted plants, the SPEI not easily applicable to potted plants, because the SPEI uses the monthly (or weekly) difference between precipitation and potential evapotranspiration [33]. To solve this difficulty, we introduced the Cumulative Water Index (CWI), which is a novel index defined as the soil moisture content cumulated for any number of past days, which can consider the past history of the soil moisture status. Then, we examined the responsivity and clonal variations of phenotypic traits to the CWI.

Cryptomeria japonica is a major forestry species in Japan, accounting for about $44 \%$ of the area used for plantations [34]. It grows relatively quickly, the wood is light and soft with excellent workability, and it is used for structural materials, such as pillars and interior building materials. This species is highly sensitive to drought [35] due to its high water demand and high transpiration [36]. Consequently, water stress has a marked negative effect on its growth.

The purpose of this study was to clarify the phenotypic variation in stomatal responses and photosynthesis activity associated with drought stress in C. japonica. To achieve this goal, we investigated the clonal variation in growth, stomatal response, and photosynthesis activity in response to drought stress among plus-tree clones of $C$. japonica using a high-throughput phenotyping method based on infrared thermography and chlorophyll fluorescence. Moreover, a statistical model that considered the cumulative soil moisture environment was used to clarify the drought resistance characteristics among the clones. The relationships between the growth, stomatal response, and chlorophyll fluorescence, as a proxy of photosynthesis activity, of $C$. japonica in response to drought stress and the soil water environment, considering the past history of soil conditions, are also discussed. 


\section{Materials and Methods}

\subsection{Tree Materials and Drought Treatments}

Cuttings of four C. japonica plus-tree clones (GO1, KA7, TE11, and TS1) were used as the experimental materials in this study. For clonal propagation of cuttings, scions were collected and placed in rooting medium (Kanuma soil) in March 2014. After rooting, cuttings were planted in 3-L pots containing a mixed-culture soil consisting of Kanuma soil, Akadama soil, and gardening soil amended with fertilizer (2:3:4.4) in March 2015 and grown for one year in a greenhouse. In February 2016, the plants were transplanted to 13.5-L plastic pots containing the same mixed-culture soil and were reared in a greenhouse with sufficient water until the drought stress experiments were started. After three months of acclimatization by keeping the same watering scheme, cuttings were randomly assigned to one of two treatments: no watering (drought) and normal watering (control). Table 1 shows the seedling height of each clone at the time the experiment was started. The experiment lasted for 85 days, from 9 May to 1 August 2016. In the drought treatment, watering was withheld from 9 May until the end of the experiment, while the control cuttings were watered three times a week for the duration of the experiment. Figure S1 shows the temporal changes in the soil water contents in the two treatments.

Table 1. Mean height of the four clones at the start of the experiment.

\begin{tabular}{ccccc}
\hline Clone Name & Treatment & $\boldsymbol{n}$ & Height $\mathbf{( c m})$ & SD \\
\hline \multirow{2}{*}{ GO1 } & Control & 5 & 38.5 & 5.0 \\
& Drought & 5 & 37.7 & 5.9 \\
KA7 & Control & 5 & 42.9 & 9.9 \\
& Drought & 5 & 44.5 & 3.7 \\
\multirow{2}{*}{ TE11 } & Control & 5 & 39.2 & 3.6 \\
& Drought & 5 & 34.8 & 4.4 \\
TS1 & Control & 5 & 50.3 & 5.1 \\
& Drought & 5 & 48.9 & 3.6 \\
\hline
\end{tabular}

\subsection{Measurement of Leaf Temperature and Calculation of Stomatal Conductance Index}

Leaves of C. japonica are composed of blanchlets with many small needles; the "leaf" in this manuscript means an about 10-20-cm-long blanchlet composed of the current year shoot and many needles. Leaf temperature was estimated using an infrared thermal camera (InfReC R300SR, Nippon Avionics, Yokohama, Japan), which measured the infrared emissions at wavelengths $8-14 \mu \mathrm{m}$ at a thermal resolution of $0.03{ }^{\circ} \mathrm{C}$ and images with a spatial resolution of $320 \times 240$ pixels. When measuring individual leaves, two reference leaves were prepared from another individual that was not used in the experiment, because it was confirmed in previous test that there was no difference in the temperature of reference leaves depending on the clone or individual used for the reference: leaves with fully opened stomata (wet reference leaves) and those with fully closed stomata (dry reference leaves). Wet reference leaves were leaves that were sprayed regularly with water to maintain their moisture level. Dry reference leaves were coated with a mixtures of petroleum jelly and liquid paraffin (1:2 by weight). The reference leaves were then removed and placed in the same image capture frame as the leaves targeted for measurements (Figure S2). One pair of the reference leaves was used for all individuals in each measurement day. Thermal images were obtained once a week at 10:00-12:00 in a greenhouse at an adjusted photosynthetically active radiation (PAR) (range of about 200 to $380 \mu \mathrm{mol} \mathrm{m}^{-2} \mathrm{~s}^{-1}$ ). When it was fine or slightly cloudy weather, PAR was controlled by covering the ceiling of the green house using a nonwoven curtain (about $80 \%$ shading rate) to avoid an excess of increasing leaf temperature because of direct solar radiation. Thermal images were obtained 11 times in experimental period, and one leaf of each individual was measured each time.

Software (InfReC Analyzer NS9500 Lite, Nippon Avionics) was used for image analysis and data extraction. Pixels of current and the previous year leaves were manually selected in the images, and the average value of the temperature of those pixels was used as the leaf 
temperature of an individual plant $\left(T_{p}\right)$. The temperatures of the dry and wet reference leaves ( $T_{d}$ and $T_{w}$, respectively) were obtained using the same procedure as that used to calculate the $T_{p}$. The stomatal conductance index $(I g)$ was calculated using the following formula [17]:

$$
\operatorname{Ig}=\left(T_{d}-T_{p}\right) /\left(T_{p}-T_{w}\right)
$$

To clarify the effect of drought stress on stomatal conductance, the $I g$ ratio (RIg) for each clone was calculated as follows:

$$
\mathrm{RIg}_{i}=I g_{d i} / I g_{c i}
$$

where $\mathrm{RIg}_{i}$ is the $I g$ ratio of the $i$ th clone, $I g_{d i}$ is the mean value of $I g$ for the $i$ th clone in the drought treatment, and $I g_{c i}$ is the mean value of $I g$ for the $i$ th clone in the control treatment. The RIg values of less than unity mean the decrease of stomatal conductance due to drought treatment.

\subsection{Measurement of Actual Stomatal Conductance}

To confirm the accuracy of the $I g$, during the drought experiment, we checked the relationship between the Ig obtained by the infrared thermography and actual stomatal conductance obtained by a gas exchange method using the other individuals of same four clones that were not used in the drought experiment. The individual samples were grown under varied soil water conditions and were measured under several environmental conditions (soil water content (SWC): $0.05-0.48 \mathrm{~cm}^{3} \mathrm{~cm}^{-3}$, ambient temperature: 24.9-34.5 ${ }^{\circ} \mathrm{C}$, and relative humidity: $52.5-70 \%$, PAR: $300-1500 \mu \mathrm{mol} \mathrm{m}^{-2} \mathrm{~s}^{-1}$ ) to a cover wider range of stomatal conductance. The actual stomatal conductance was measured by using a portable gas exchange system (LI-6400, LI-COR, Lincoln, NE, USA) and the conifer chamber (6400-22L, LI-COR) with the LED light source intensity, temperature, relative humidity, and $\mathrm{CO}_{2}$ concentration in the chamber set to the same values as the ambient conditions. After allowing the stomatal conductance to reach a steady state, stomatal conductance was recorded five times every minute. After the measurements, the leaf surface temperature of the same individual was measured immediately by infrared thermography under the same conditions of measuring the actual stomatal conductance. Then, the leaves whose actual stomatal conductance was measured were cut off and dried in an oven at $105^{\circ} \mathrm{C}$ for 2 days; the oven-dried weight was measured, and the stomatal conductance per biomass ( $\mathrm{mol} \mathrm{g}^{-1} \mathrm{~s}^{-1}$ ) was calculated. The average of these values was used as the actual stomatal conductance of an individual cutting under ambient conditions. After that, the actual stomatal conductance and the $I g$ were compared.

\subsection{Measurement of Maximum Photochemical Quantum Yield (Fv/Fm)}

The maximum photochemical quantum yield of photosystem II (PS II) (Fv/Fm), which is an index of the photosynthetic ability under water deficit conditions, was measured by the chlorophyll fluorescence method. Chlorophyll fluorescence parameters were obtained using a pulse-amplitude modulation fluorometer (MINI-PAM, Walz, Bayern, Germany). Thirty minutes after sunset, the minimum fluorescence level (Fo) was determined with a low-intensity measuring light. The maximum fluorescence level $(F m)$ was measured after a 0.5 s saturating pulse at $4000 \mu \mathrm{mol} \mathrm{m} \mathrm{m}^{-2} \mathrm{~s}^{-1}$. Fv/Fm was calculated as follows:

$$
F v / F m=(F m-F o) / F m
$$

Fv/Fm was measured once a week at the same time as the measurements of the infrared thermograph were conducted, and an average of three measurements per individual was used as the Fv/Fm of the focal individual.

$$
\mathrm{R} F v / F m_{i}=\left(F v / F m_{d i}\right) /\left(F v / F m_{c i}\right)
$$


where $\mathrm{RFv} / \mathrm{Fm}_{i}$ is the $\mathrm{Fv} / \mathrm{Fm}$ ratio of the $i$ th clone, and $F v / F m_{d i}$ and $F v / F m_{c i}$ are the mean values of the $\mathrm{Fv} / \mathrm{Fm}$ of the $i$ th clone in the drought and control treatments, respectively.

\subsection{Measurement of Growth}

Axial growth was measured as a growth trait. Before the beginning of the experiment, a line was drawn at a point $5 \mathrm{~cm}$ below the apex of the main shoot with a black marker. The distance from the mark to the shoot apex was then measured weekly, and the length differentials were regarded as the amount of shoot growth or growth rate. To clarify the effect of drought stress on growth, the growth rate ratio (GRR) was calculated for each clone as follows:

$$
\mathrm{GRR}_{i}=\mathrm{GR}_{d i} / \mathrm{GR}_{c i}
$$

where $\mathrm{GRR}_{i}$ is the growth rate ratio of the $i$ th clone, and $\mathrm{GR}_{d i}$ and $\mathrm{GR}_{c i}$ are the mean values of the growth rate of the $i$ th clone in the drought and control treatments, respectively.

\subsection{Measurement of Soil Condition}

The soil water content (SWC; $\mathrm{cm}^{3} \mathrm{~cm}^{-3}$ ) during the experiment was measured using a soil moisture sensor (SM150 Soil Moisture Kit, Delta-T Devices, Cambridge, UK). The SWC was measured by inserting the sensor into the soil at three points in each pot, and the average value was used as the SWC of the pot. Measurement of the SWC was conducted every one or two days. Relationship between the soil water content and soil water potential of the mixed culture soil used in the experiment is shown in Figure S3.

\subsection{Statistical Analysis}

To investigate the tree responses to cumulative drought stress, the novel CWI was defined as follows:

$$
\mathrm{CWI}_{d p}=\sum_{k=d+1-p}^{d} \mathrm{SWC}_{k}
$$

where $\mathrm{SWC}_{k}$ is the soil water content $\left(\mathrm{cm}^{3} \mathrm{~cm}^{-3}\right)$ of $k$ th day; $d$ is the number of days since the start of the experiment $(0 \leq d \leq 84) ; p$ is an arbitrary number of days from $d(p=1,2$, $3,4,5,6,7,10,14,21,28,35,42,49,56,63,70,77$, and 84); and CPDs is the cumulative number of past days $p$ days from $d+1-p$ to $d$ day, in which 1 CPD corresponds to a simple SWC. Since the soil water conditions of the two treatment classes were similar before starting the drought stress experiments, when calculating the CWI before the starting day of the experiment (i.e., $d+1-p<0$ ), the SWCs of the drought treatment class before the experiment $(d=0)$ were assumed to be similar to the mean value of SWC in the control class during the overall experimental period $\left(0.461 \mathrm{~cm}^{3} \mathrm{~cm}^{-3}\right)$. Since SWC was measured every 1 or 2 days, these data were not available for every day of the experimental period. Therefore, the SWC for nonmeasurement days was estimated by linear interpolation.

To simulate C. japonica responses to drought stress, the responsiveness of RIg, GRR, and RFv/Fm to the CWI and the clonal effects were modeled using a nonlinear mixed-effect model (NLMM). The Gompertz function was used to fit the responses of RIg and GRR to the CWI (Equation (7)). Additionally, the von Bertalanffy function was used to fit the response of RFv/Fm to the CWI (Equation (8)).

$$
\begin{gathered}
y_{i j}=\exp \left(-\alpha \times \exp \left(-\beta \times \mathrm{CWI}_{i j}\right)\right)+e_{i j} \\
y_{i j}=1-\exp \left(-\beta \times\left(\mathrm{CWI}_{i j}-\alpha\right)\right)+e_{i j}
\end{gathered}
$$

where $y_{i j}$ is the response variable (RIg, GRR, or RFv/Fm) of $j$ th time point of the $i$ th individual; $\alpha$ and $\beta$ are the parameters of the Gompertz and von Bertalanffy functions; $\mathrm{CWI}_{i j}$ is the explanatory variable of the $j$ th time point for the $i$ th individual; and $e_{i j}$ is the 
random residual. Each of the parameters $\alpha$ and $\beta$ can be described by a linear mixed-effects model. The full models for observation $j$ of individual $i$ are

$$
\begin{gathered}
y_{i j}=\exp \left(-\left(b_{\alpha i j}+c_{\alpha i}\right) \times \exp \left(-\left(b_{\beta i j}+c_{\beta i}\right) \times \mathrm{CWI}_{i j}\right)\right)+e_{i j} \\
y_{i j}=1-\exp \left(-\left(b_{\alpha i j}+c_{\alpha i}\right) \times\left(\mathrm{CWI}_{i j}-\left(b_{\beta i j}+c_{\beta i}\right)\right)\right)+e_{i j}
\end{gathered}
$$

where $b$ is a vector of the fixed effects, and $c$ is a vector of the random clonal effects.

The application of NLMMs was used to clarify the clonal response in three traits: $\mathrm{RIg}$, GRR, and RFv/Fm against drought stress. The CWI values were used as explanatory variables in NLMMs to consider the cumulative effect of past soil water conditions. The CPD, which was used to calculate the CWI, was serially changed from 1 to 84 days, and the optimum CPD was determined based on the Akaike's Information Criterion (AIC) for each of the three traits. NLMM analysis was performed using the LME4 package in $\mathrm{R}[37,38]$, and the statistical significance of the random effect parameters (i.e., among-clone difference) were tested using the analysis of deviance.

\section{Results}

\subsection{Ig and Actual Stomatal Conductance}

Figure 1 shows the relationship between the actual stomatal conductance and the Ig. Both traits were measured on 27 July, 2 August, and 1 October, and the relationships between the two traits were determined on each measurement day. The relationships between the actual stomatal conductance and the $I g$ on all measured days were significantly and positively correlated $(r=0.83,0.66$, and 0.78 and $p<0.01,0.001$, and 0.05 , respectively).
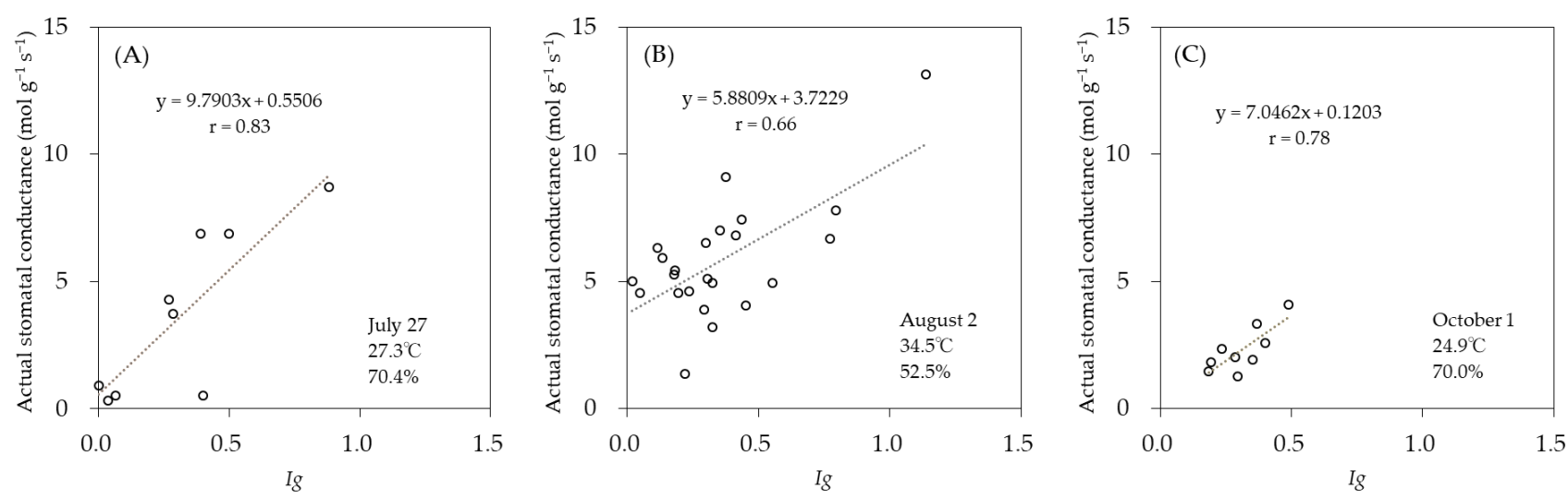

Figure 1. Relationship between the stomatal conductance index (Ig) estimated by the leaf temperature and actual stomatal conductance measured by gas exchange. The measurements in (A-C) were measured on different days: 27 July, 2 August, and 1 October, respectively.

\subsection{Stomatal Conductance Response}

Figure 2 shows the weekly changes in Ig from 9 May to 1 August. The Ig values for GO1 and KA7 in the drought treatment were significantly lower than those of the controls at 21 days post-treatment (dpt), while, in both TE11 and TS1, the first significant differences between the control and drought treatments were observed at $14 \mathrm{dpt}$. As the experiment progressed, Ig approached zero at $28 \mathrm{dpt}$ in KA7 and TS1 and at $56 \mathrm{dpt}$ in GO1 and TE11. As shown in Figure 3, the RIg tended to decrease with the SWC under the conditions of drought treatment. In C. japonica, the RIg tended to decrease towards zero when the SWC decreased from about $0.25 \mathrm{~cm}^{3} \mathrm{~cm}^{-3}$ to $0.15 \mathrm{~cm}^{3} \mathrm{~cm}^{-3}$. 
(A) GO1

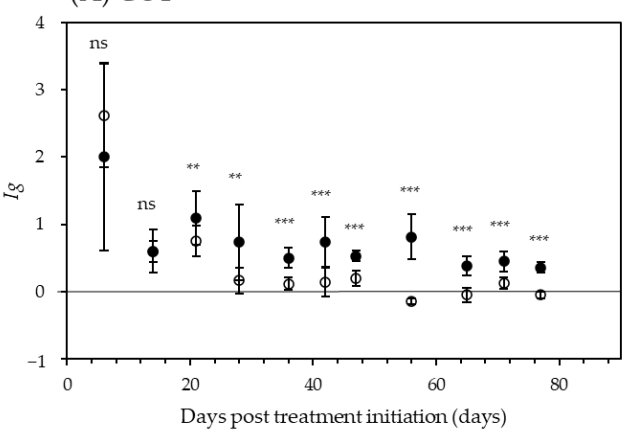

(C) TE11

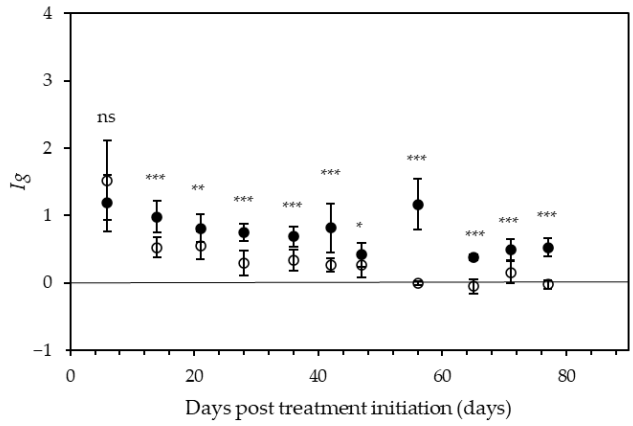

(B) KA7

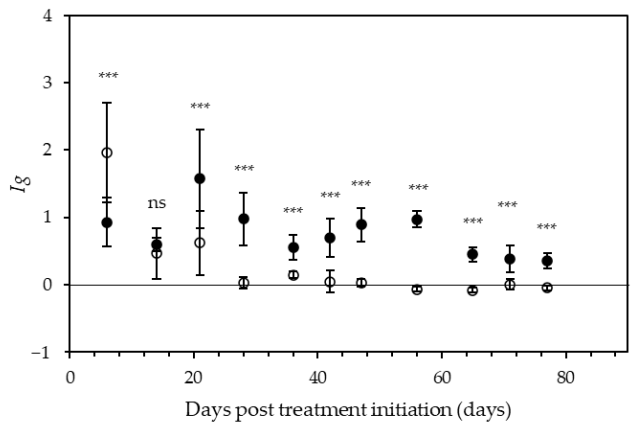

(D) TS1

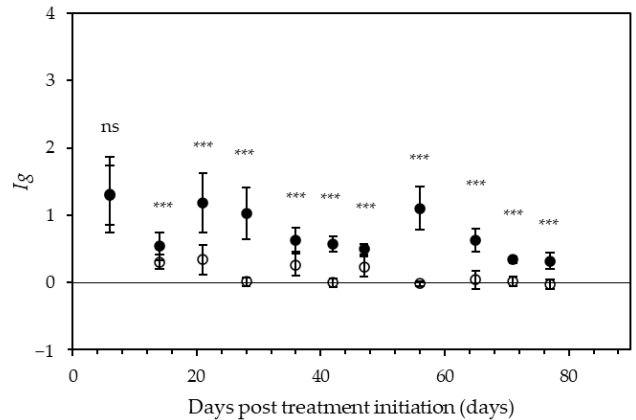

Figure 2. Changes in the stomatal conductance index $(I g)$ in the four clones. (A-D) show the results obtained for GO1, KA7, TE11, and TS1, respectively. Open and closed circles denote the drought and control treatments. Statistically significant differences in the Ig between treatments at each day post-treatment (dpt) for each clone were evaluated by Student's $t$-test (ns: not significant, $*: p<0.1, * *: p<0.05$, and ${ }^{* * *}: p<0.01$ ).

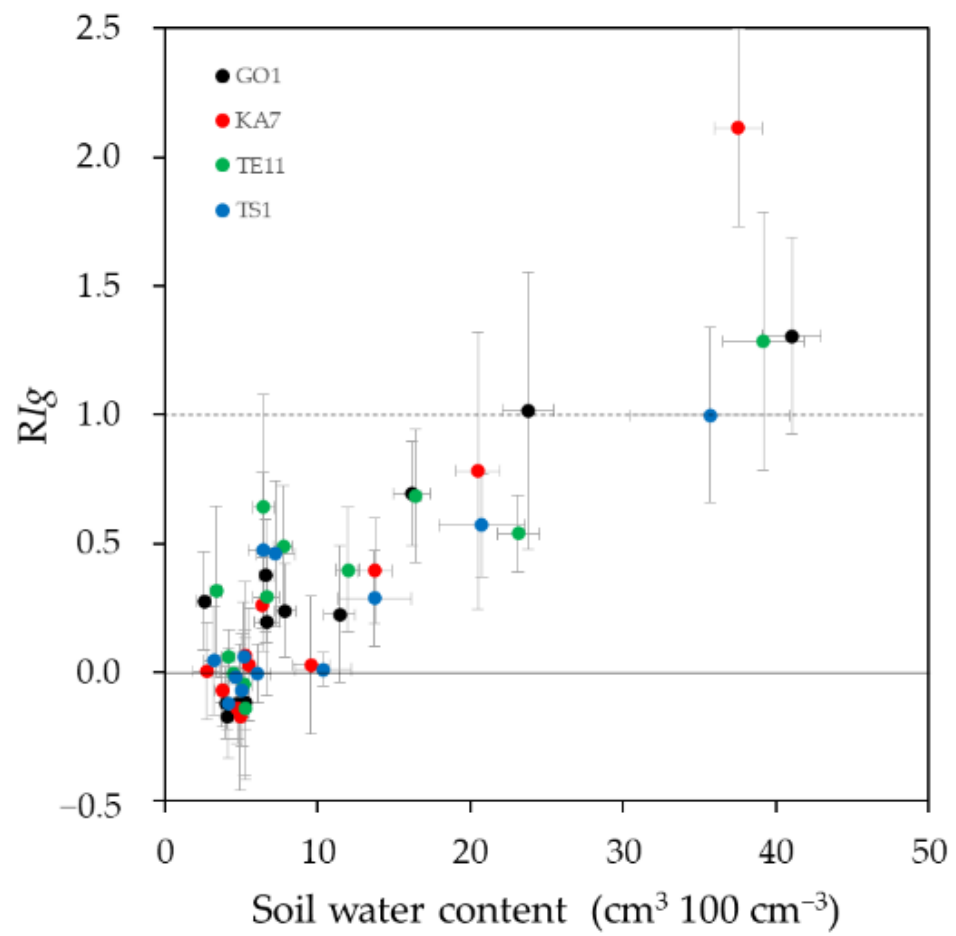

Figure 3. Relationship between the stomatal conductance index ratio (RIg) and the soil water content under the conditions of drought treatment. Black, red, green, and blue correspond to the clones GO1, KA7, TE11, and TS1, respectively. 


\subsection{Growth Rate}

Figure 4 shows the change in the temporal growth rates of four clones during the experiment. In the control treatment, the growth in all four clones peaked at around $21 \mathrm{dpt}$ (30 May) before decreasing. The growth in KA7 and TE11 ceased at $77 \mathrm{dpt}$ (25 July), whereas the growth in GO1 and TS1 was maintained at 0.52 and $2.14 \mathrm{~cm} /$ week, respectively. As in the control treatment, the growth peaked at around $21 \mathrm{dpt}$ in the drought treatment. The growth rate of TS1 in the drought treatment decreased significantly after $21 \mathrm{dpt}$ compared to the control, and the reduction became evident earlier than in the other clones. GO1, KA7, and TE11 exhibited significantly reduced growth after $28 \mathrm{dpt}, 28 \mathrm{dpt}$, and $35 \mathrm{dpt}$, respectively. In the drought treatment, KA7 and TS1 ceased growing at $49 \mathrm{dpt}$, GO1 at $56 \mathrm{dpt}$, and TE11 at $63 \mathrm{dpt}$. As shown in Figure 5, the GRRs tended to decrease with the SWC under the conditions of drought treatment. In C. japonica, the GRR tended to decrease towards zero when the SWC decreased from about $0.20 \mathrm{~cm}^{3} \mathrm{~cm}^{-3}$ to $0.10 \mathrm{~cm}^{3} \mathrm{~cm}^{-3}$.

\section{4. $\mathrm{Fv} / \mathrm{Fm}$}

The Fv/Fm exhibited similar values until the middle of the experiment, whereafter an abrupt decrease in Fv/Fm became evident in TS1 and KA7 at $77 \mathrm{dpt}$ and in GO1 and TE11 after $84 \mathrm{dpt}$ (Figure 6). As the drought conditions progressed, at $84 \mathrm{dpt}$, the $\mathrm{Fv} / \mathrm{Fm}$ value of some Ts1 and KA7 cuttings decreased to zero. Figure 7 shows the relationship between the soil water content and $\mathrm{RFv} / \mathrm{Fm}$. The RFv/Fm started to decrease sharply at around $0.05 \mathrm{~cm}^{3} \mathrm{~cm}^{-3}$ of the SWC.

(A) GO1

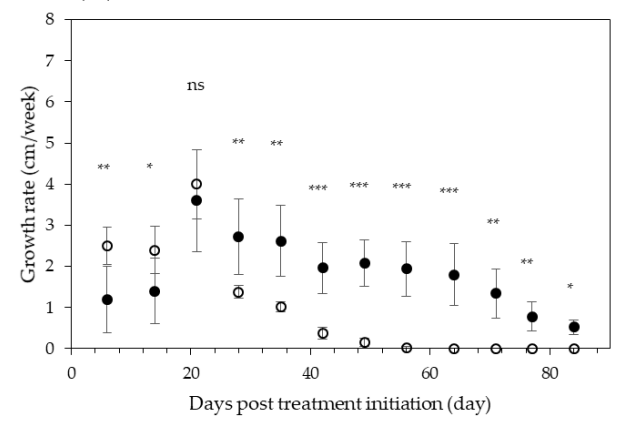

(C) TE11

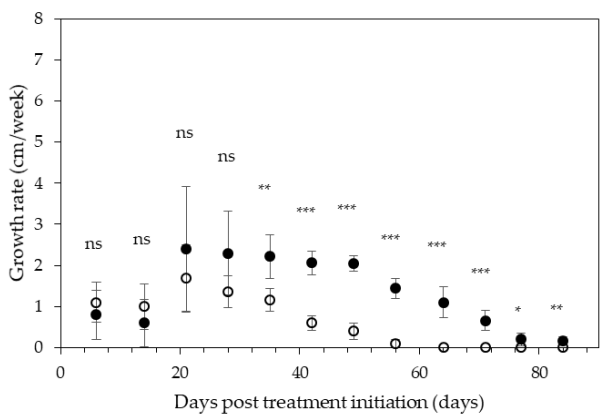

(B) KA7

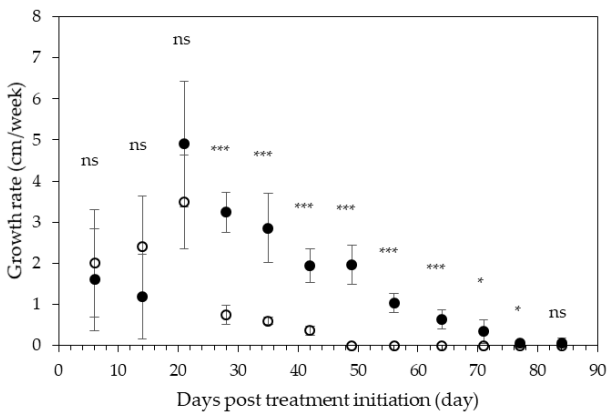

(D) TS1

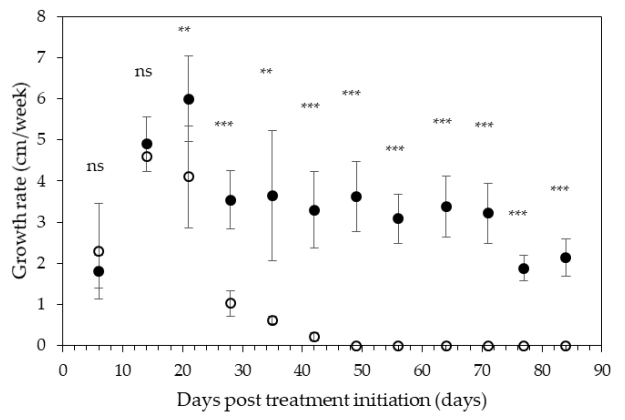

Figure 4. Temporal changes in the growth rates in the four clones. (A-D) show the results of GO1, KA7, TE11, and TS1, respectively. Open and closed circles denote the drought and control treatments. Statistical significance of the growth rates between treatments at each dpt for each clone was evaluated by Student's $t$-test (ns: not significant, ${ }^{*}: p<0.1,{ }^{* *}: p<0.05$, and ${ }^{* * *}: p<0.01$ ). 


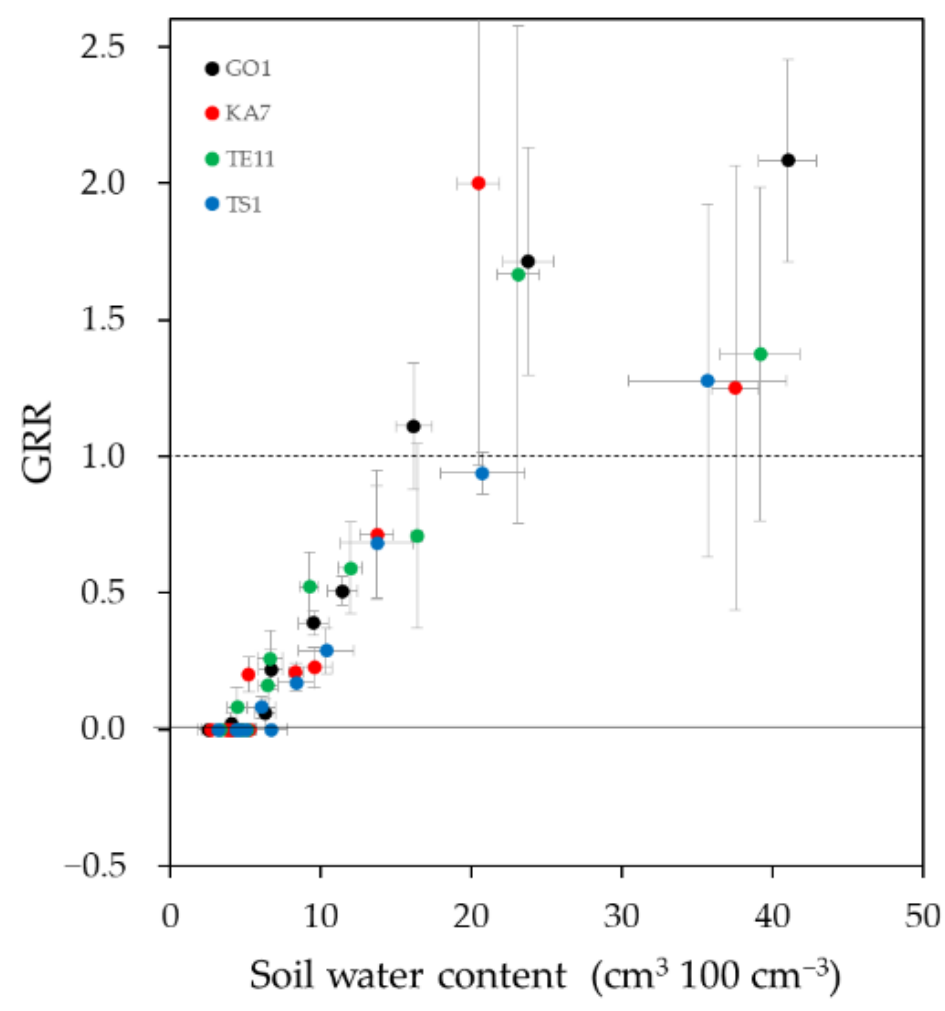

Figure 5. Relationship between the soil water content and growth rate ratio (GRR). Black, red, green, and blue symbols correspond to the clones GO1, KA7, TE11, and TS1, respectively.

(A) GO1

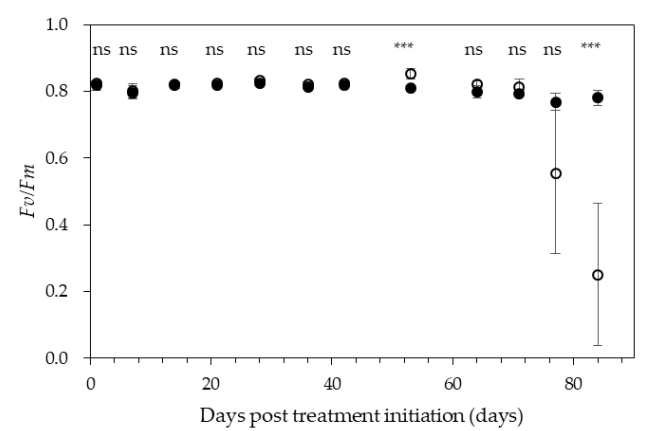

(C) TE11

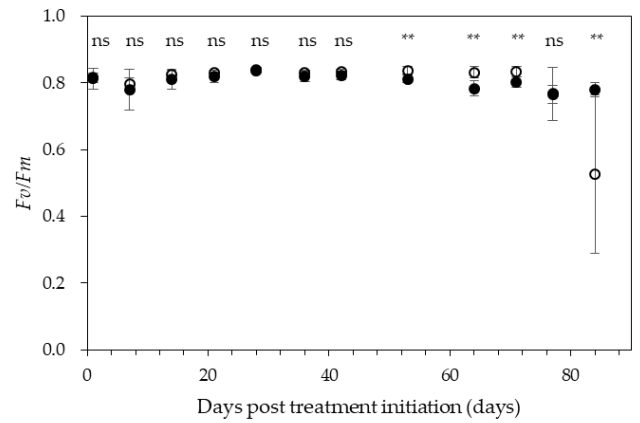

(B) KA7

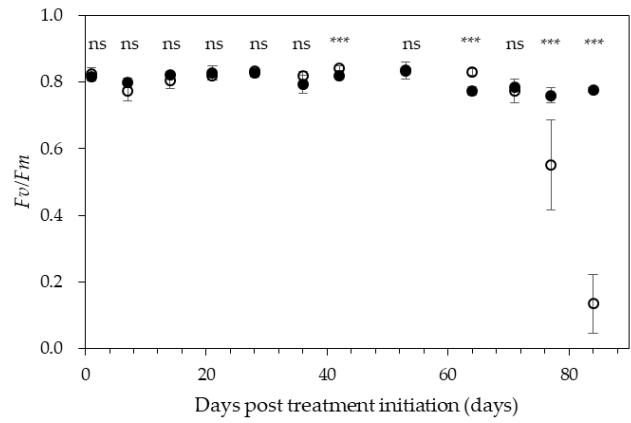

(D) TS1

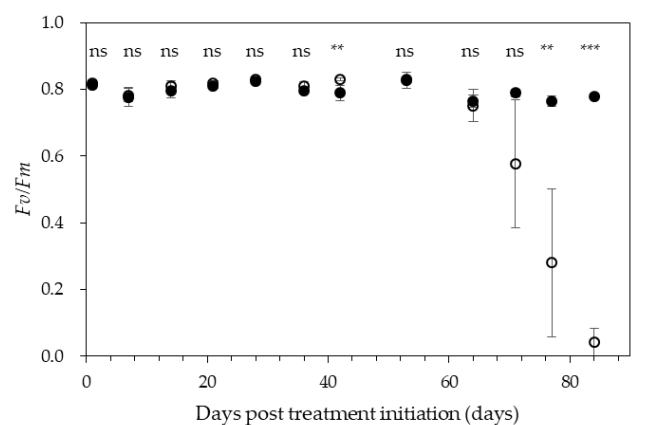

Figure 6. Temporal changes in the maximum photochemical quantum yield of photosystem II (Fv/Fm) in the four clones. (A-D) show the results obtained for GO1, KA7, TE11, and TS1, respectively. Open and closed circles denote the drought and control treatments. Statistical significance of the Fv/Fm between treatments at each dpt for each clone was evaluated by Student's $t$-test (ns: not significant, ${ }^{* *}: p<0.05$, and $\left.{ }^{* * *}: p<0.01\right)$. 


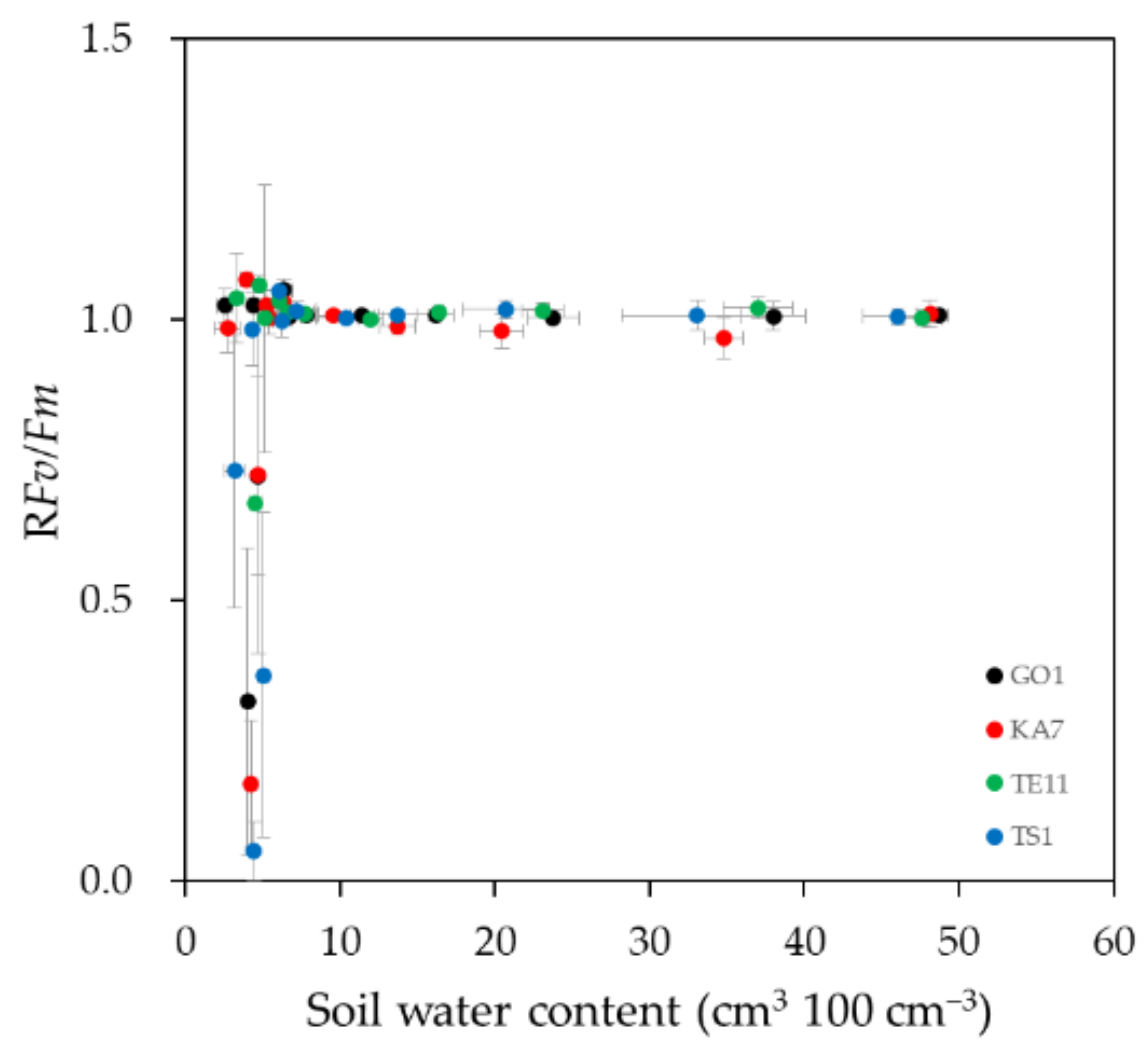

Figure 7. Relationship between the soil water content and RFv/Fm. The black, red, green, and blue symbols correspond to the clones GO1, KA7, TE11, and TS1, respectively.

\subsection{Optimization of CPD for CWI Using an NLMM}

According to our NLMM analyses incorporating random effects for the responses of different clones in the model, the optimum CPDs were estimated on the basis of the lowest AIC values for each trait (Table 2). The models were applied to the pooled data of the four clones. The patterns of the changes in the AICs differed among the three traits. The AIC of the $\mathrm{RIg}$ reached a minimum value at $2 \mathrm{CPD}$, before increasing again thereafter (Table 2). The AIC of the GRR decreased until 21 CPD before increasing thereafter (Table 2). The AIC of the RFv/Fm values decreased gradually and then reached a minimum value at $70 \mathrm{CPD}$ (Table 2). These findings imply that the response in the RFv/Fm was best explained by longer cumulative soil water conditions (i.e., the previous 70 days), whereas the RIg was best explained by shorter cumulative soil water conditions (i.e., the previous two days). We estimated the responses of the three traits in the four clones using an NLMM and the CWI at the optimized CPD. Regarding the RIg, KA7 responded the fastest, with an increase in the CWI, followed by TS1, GO1, and TE11 in order (Figure 8A). Thus, KA7 exhibited the most sensitive reduction in stomatal conductance under conditions of drought stress. Conversely, TE11 responded the slowest to drought stress. In terms of the GRR, the clonal response was thus in the order of TS1, KA7, GO1, and TE11 (Figure 8B), and in terms of the $\mathrm{RFv} / \mathrm{Fm}$, it was TS1, GO1, KA7, and TE11 (Figure 8C). The random effect parameters $\alpha$ and $\beta$ representing the differences among the clones in responsivity to drought stress were significant, except for the $\beta$ of RIg (Table 3). 
Table 2. Parameter estimates and Akaike's information criteria (AIC) used in the models. For the maximum photochemical quantum yield of photosystem II (RFv/Fm), model algorism did not converge for $p=1,2,3,4$, and 5. RIg: stomatal conductance index ratio and GRR: growth rate ratio. CWI: Cumulative Water Index.

\begin{tabular}{|c|c|c|c|c|c|c|c|c|}
\hline \multirow{2}{*}{ Traits } & \multirow{2}{*}{$p$} & \multirow{2}{*}{ Model Expression } & \multicolumn{2}{|c|}{ Fixed Effects } & \multicolumn{3}{|c|}{ SD of Random Effects } & \multirow{2}{*}{ AIC } \\
\hline & & & $\alpha$ & $\beta$ & $\alpha$ & $\beta$ & Residual & \\
\hline \multirow{19}{*}{$\mathrm{R} I g$} & 1 & \multirow{19}{*}{$\begin{array}{c}\mathrm{CWI}_{d p}=\sum_{k=d+1-p}^{d} \mathrm{SWC}_{k} \\
y_{i j}=\exp \left(-\alpha \times \exp \left(-\beta \times \mathrm{CWI}_{i j}\right)\right)+e_{i j}\end{array}$} & 3.839 & 4.771 & 0.804 & 0.004 & 0.276 & 74.346 \\
\hline & 2 & & 3.758 & 4.719 & 0.778 & 0.021 & 0.273 & 70.747 \\
\hline & 3 & & 3.546 & 4.439 & 0.761 & 0.000 & 0.273 & 70.997 \\
\hline & 4 & & 3.396 & 4.326 & 0.745 & 0.000 & 0.274 & 71.748 \\
\hline & 5 & & 3.306 & 4.198 & 0.721 & 0.010 & 0.274 & 72.307 \\
\hline & 6 & & 3.263 & 4.082 & 0.716 & 0.006 & 0.275 & 72.954 \\
\hline & 7 & & 3.424 & 3.896 & 0.728 & 0.001 & 0.275 & 73.606 \\
\hline & 10 & & 3.285 & 3.558 & 0.736 & 0.016 & 0.276 & 75.027 \\
\hline & 14 & & 3.300 & 3.180 & 0.785 & 0.002 & 0.276 & 75.658 \\
\hline & 21 & & 3.464 & 2.758 & 0.914 & 0.002 & 0.277 & 77.202 \\
\hline & 28 & & 3.725 & 2.536 & 1.072 & 0.029 & 0.280 & 82.932 \\
\hline & 35 & & 4.084 & 2.462 & 1.163 & 0.000 & 0.280 & 84.219 \\
\hline & 42 & & 4.536 & 2.476 & 1.305 & 0.063 & 0.280 & 83.060 \\
\hline & 49 & & 5.533 & 2.619 & 1.537 & 0.003 & 0.279 & 81.112 \\
\hline & 56 & & 7.396 & 2.898 & 2.031 & 0.141 & 0.278 & 80.770 \\
\hline & 63 & & 8.739 & 3.067 & 0.290 & 0.393 & 0.279 & 81.607 \\
\hline & 70 & & 11.031 & 3.302 & 0.286 & 0.388 & 0.279 & 81.484 \\
\hline & 77 & & 11.996 & 3.386 & 0.284 & 0.386 & 0.279 & 81.442 \\
\hline & 84 & & 12.319 & 3.413 & 0.284 & 0.386 & 0.279 & 81.429 \\
\hline \multirow{19}{*}{ GRR } & 1 & \multirow{19}{*}{$\begin{array}{c}\mathrm{CWI}_{d p}=\sum_{k=d+1-p}^{d} \mathrm{SWC}_{k} \\
y_{i j}=\exp \left(-\alpha \times \exp \left(-\beta \times \mathrm{CWI}_{i j}\right)\right)+e_{i j}\end{array}$} & 7.578 & 9.995 & 1.177 & 0.000 & 0.155 & -181.317 \\
\hline & 2 & & 7.276 & 9.731 & 1.242 & 0.001 & 0.153 & -186.424 \\
\hline & 3 & & 6.974 & 9.453 & 1.257 & 0.004 & 0.151 & -189.880 \\
\hline & 4 & & 6.759 & 9.324 & 1.252 & 0.016 & 0.151 & -190.601 \\
\hline & 5 & & 6.538 & 9.290 & 1.156 & 0.000 & 0.151 & -191.492 \\
\hline & 6 & & 6.051 & 9.031 & 1.029 & 0.000 & 0.151 & -191.246 \\
\hline & 7 & & 5.566 & 8.404 & 0.976 & 0.006 & 0.151 & -192.244 \\
\hline & 10 & & 5.316 & 7.655 & 0.911 & 0.119 & 0.149 & -197.066 \\
\hline & 14 & & 4.667 & 6.284 & 0.750 & 0.379 & 0.148 & -200.229 \\
\hline & 21 & & 4.412 & 4.738 & 0.625 & 0.549 & 0.146 & -203.677 \\
\hline & 28 & & 4.626 & 3.954 & 0.003 & 0.556 & 0.149 & -193.514 \\
\hline & 35 & & 6.224 & 3.908 & 0.003 & 0.471 & 0.151 & -187.846 \\
\hline & 42 & & 11.424 & 4.452 & 0.118 & 0.427 & 0.153 & -184.530 \\
\hline & 49 & & 23.552 & 5.181 & 0.140 & 0.408 & 0.153 & -184.231 \\
\hline & 56 & & 46.862 & 5.873 & 0.144 & 0.392 & 0.152 & -184.386 \\
\hline & 63 & & 92.042 & 6.550 & 0.145 & 0.381 & 0.152 & -184.564 \\
\hline & 70 & & 167.363 & 7.150 & 0.157 & 0.373 & 0.152 & -184.683 \\
\hline & 77 & & 255.696 & 7.575 & 0.156 & 0.368 & 0.152 & -184.752 \\
\hline & 84 & & 323.788 & 7.811 & 0.156 & 0.366 & 0.152 & -184.786 \\
\hline \multirow{14}{*}{$\mathrm{RFv} / F m$} & 1 & \multirow{14}{*}{$\begin{array}{c}\mathrm{CWI}_{d p}=\sum_{k=d+1-p}^{d} \mathrm{SWC}_{k} \\
y_{i j}=1-\exp \left(-\beta \times\left(\mathrm{CWI}_{i j}-\alpha\right)\right)+e_{i j}\end{array}$} & & & & & & - \\
\hline & 2 & & & & & & & - \\
\hline & 3 & & & & & & & - \\
\hline & 4 & & & & & & & - \\
\hline & 5 & & & & & & & - \\
\hline & 6 & & -0.040 & 22.590 & 0.035 & 0.215 & 0.213 & -42.095 \\
\hline & 7 & & -0.028 & 27.666 & 0.025 & 0.209 & 0.209 & -50.825 \\
\hline & 10 & & -0.024 & 32.737 & 0.026 & 0.201 & 0.203 & -63.955 \\
\hline & 14 & & 0.000 & 57.847 & 0.012 & 0.172 & 0.172 & -141.472 \\
\hline & 21 & & 0.003 & 69.171 & 0.009 & 0.138 & 0.138 & -245.302 \\
\hline & 28 & & 0.002 & 63.303 & 0.009 & 0.135 & 0.135 & -255.212 \\
\hline & 35 & & 0.002 & 53.494 & 0.010 & 0.129 & 0.129 & -278.650 \\
\hline & 42 & & 0.001 & 43.527 & 0.011 & 0.124 & 0.124 & -296.940 \\
\hline & 49 & & -0.001 & 32.963 & 0.014 & 0.119 & 0.119 & -314.384 \\
\hline
\end{tabular}


Table 2. Cont.

\begin{tabular}{|c|c|c|c|c|c|c|c|c|}
\hline \multirow{2}{*}{ Traits } & \multirow{2}{*}{$p$} & \multirow{2}{*}{ Model Expression } & \multicolumn{2}{|c|}{ Fixed Effects } & \multicolumn{3}{|c|}{ SD of Random Effects } & \multirow{2}{*}{ AIC } \\
\hline & & & $\alpha$ & $\beta$ & $\alpha$ & $\beta$ & Residual & \\
\hline \multirow{5}{*}{$\mathrm{RFv} / F m$} & 56 & & -0.002 & 25.681 & 0.016 & 0.117 & 0.117 & -326.460 \\
\hline & 63 & & -0.002 & 18.286 & 0.021 & 0.111 & 0.114 & -339.369 \\
\hline & 70 & & -0.004 & 12.711 & 0.032 & 0.109 & 0.111 & -348.159 \\
\hline & 77 & & -0.002 & 9.774 & 0.039 & 0.116 & 0.115 & -332.181 \\
\hline & 84 & & 0.002 & 8.631 & 0.055 & 0.127 & 0.120 & -310.388 \\
\hline
\end{tabular}
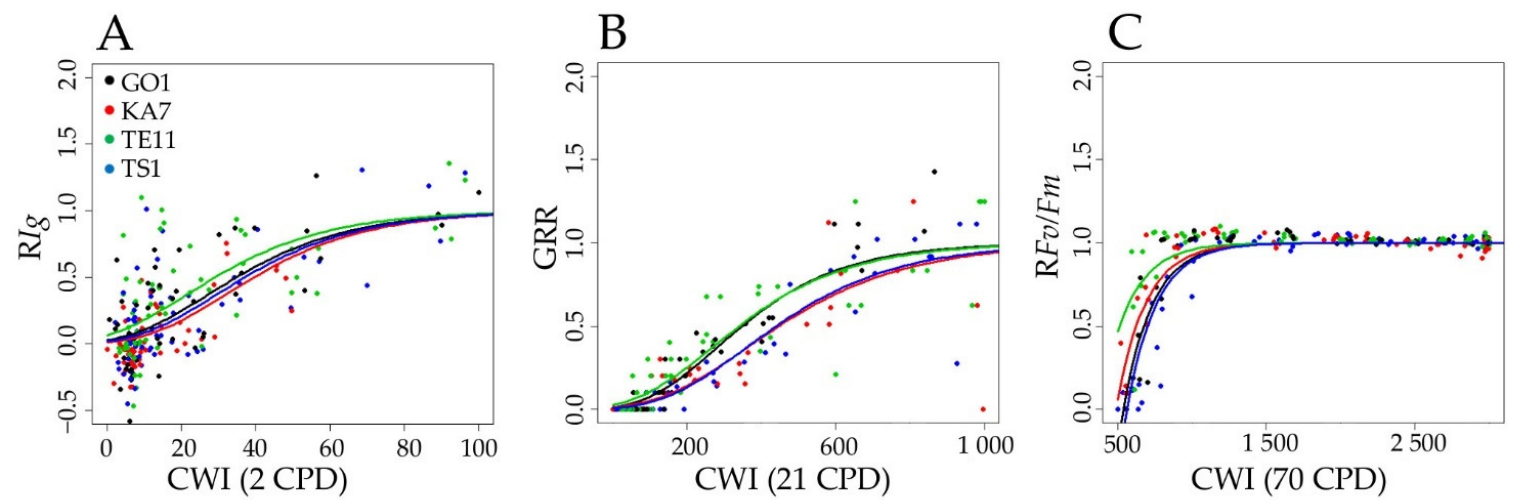

Figure 8. Responses of traits to the Cumulative Water Index (CWI) at the optimum cumulative number of past days (CPD). (A) Response to the CWI at 2 CPD in the stomatal conductance index ratio (RIg) model. (B) Response to the CWI at 21 CPD in the growth rate ratio (GRR) model. (C) Response to the CWI at $70 \mathrm{CPD}$ in the maximum photochemical quantum yield of photosystem (PS) II (RFv/Fm) model. Data points are the measured values, and the curves are the predicted clonal response estimated by the nonlinear mixed-effect model (NLMM) fitted to the Gompertz function (A,B) or the von Bertalanffy function (C). The black, red, green, and blue symbols correspond to the clones GO1, KA7, TE11, and TS1, respectively.

Table 3. Parameter estimates and variance components (VC) of the clones. The percentages of VCs are shown in parentheses, and the statistical significances of the random effects are shown as asterisks. CPD: cumulative number of past days.

\begin{tabular}{|c|c|c|c|c|c|c|c|c|c|c|c|c|}
\hline \multirow{2}{*}{ Traits } & \multirow{2}{*}{ CPD } & \multicolumn{4}{|c|}{ Estimates of Random Effects in $\alpha$} & \multicolumn{4}{|c|}{ Estimates of Random Effects in $\beta$} & \multicolumn{3}{|c|}{ Variance of Random Effects } \\
\hline & & GO1 & KA7 & TE11 & TS1 & GO1 & KA7 & TE11 & TS1 & $\alpha$ & $\beta$ & Residual \\
\hline RIg & 2 & -0.1624 & 0.7303 & -1.0108 & 0.2428 & 0.0006 & -0.0004 & 0.0001 & -0.0004 & $0.6047(88.9 \%)^{*}$ & $0.0005(0.1 \%)$ & 0.0748 \\
\hline GRR & 21 & -0.0311 & 0.0976 & -0.7285 & 0.5117 & 0.5522 & -0.5550 & 0.1700 & -0.2895 & $0.3906(2.1 \%)^{* *}$ & $0.3012(3.0 \%)^{* *}$ & 0.0212 \\
\hline $\mathrm{RFv} / \mathrm{Fm}$ & 70 & 0.0196 & -0.0008 & -0.0455 & 0.0292 & 0.0198 & 0.0197 & 0.0136 & -0.0532 & $0.0010(4.1 \%)^{* *}$ & $0.0119(46.9 \%) * *$ & 0.0124 \\
\hline
\end{tabular}

\section{Discussion}

\subsection{Application of Ig Measured by Infrared Thermography in C. japonica}

In this study, the Ig was obtained by preparing dry and wet reference leaves according to the method of Leinonen and Jones [39]. For crops and broad-leaved trees, which often have flat leaves, dry reference leaves were prepared by coating them with petroleum jelly $[17,20,39]$. In the case of $C$. japonica, which has needles with a complex steric structure, coating the leaves with a thin layer of petroleum jelly is difficult because of the high consistency of the jelly. To overcome this problem, we added paraffin, an involatile oil, to the petroleum jelly to adjust the consistency, and this enabled us to coat thoroughly the surface of the C. japonica needles. Yu et al. [20] measured the Ig of leaves from Firmiana platanifolia trees under drought conditions using dry reference leaves prepared using only petroleum jelly and found a positive correlation $r=0.85$ between the $I g$ values and actual stomatal conductance. Similarly, Leinonen and Jones [39] observed a positive correlation $r=0.44$ between the $I g$ values and actual stomatal conductance in Vicia faba. The findings of this study revealed comparable positive correlations $r=0.66$ to 0.83 between the $I g$ values and stomatal conductance, which varied depending on the environment on the 
measured day. In this study, $\mathrm{RIg}$, which is the ratio of the $I g$ value in the drought treatment to the value in the control, was adopted as the trait to evaluate the stomatal drought responses. Therefore, the stomatal responsivity to drought is successfully evaluated, even if the intercept and slope in the relationship between the Ig value and actual stomatal conductance varied among the measured days. Thus, provided that dry reference leaves are prepared with care, high-throughput measurements using infrared thermography are wellsuited for estimating stomatal conductance in C. japonica with its complex steric needles.

\subsection{Estimation of Phenotypic Trait Responses to CWI by NLMM}

To promote the breeding programs aiming at improving drought resistance, it is essential to evaluate appropriately the clonal values of traits tightly related to the physiological responses against drought stress. Drought stress has been shown to have a cumulative effect on trees [31,32], and the drought intensity in the soil, which is affected by the rate of water consumption, varies among samples depending on the size and physiological condition of the seedlings. Therefore, because seedlings' water consumption rates vary from pot to pot, it is not appropriate to use the trait values measured at a particular time point as if they would be under the same intensity of stress. Previous studies (e.g., Nanayakkara et al. [40] and Bigras [41]) used a controlled SWC or within-tissue water potential as an indicator of the intensity of the drought stress and then evaluated the performance of the stress resistance at the individual or race levels. In this study, however, as we could not perfectly control the water consumption rates of all growing seedlings, we overcame this difficulty by flexibly modeling the responses of clones to the CWI, which was introduced as an indicator of cumulative drought stress. The clonal responses to the CWI were fitted by using the Gompertz or von Bertalanffy functions; then, the optimal CPDs were searched for each trait by the AIC score basal model selection. When achieving the lowest AIC score, the good estimates of the model parameters $\alpha$ and $\beta$ were obtained, and the CWI at the optimal CPD adequately described the trait response to drought stress. Our modeling approach successfully provided an indicator reflecting both the stress duration and intensity by estimating the optimum CPD.

Functionally, parameters $\alpha$ and $\beta$ reflect the $\mathrm{x}$-intercept and slope (attenuation rate) of the curves, respectively. When the $\beta$ values are smaller, biologically, the trait value (such as GRR) more gradually approaches zero with drought stress. On the other hand, when the $\alpha$ values are larger, the trait value rapidly drops to zero, even under weak drought stress conditions. We estimated the $\alpha$ and $\beta$ values as random effect variables of the clones in the NLMM, and this modeling approach allows us to capture the trait-response curves of each clones to drought stress.

\subsection{Relationship between CPDs and Responsivity of Phenotypic Traits}

In this study, as the soil drying progressed, the phenotypic traits (RIg, GRR, and $\mathrm{RFv} / \mathrm{Fm}$ ) also declined. However, the responses to drought stress varied among the traits in the temporal order of RIg, GRR, and RFv/Fm, and the corresponding optimum CPDs were estimated as two, 21, and 70, respectively. Drought stress typically reduced the leaf water potential by inducing a decrease in stomatal opening via an abscisic acid (ABA)mediated signal transduction $[42,43]$. Stomatal closure decreases transpiration and $\mathrm{CO}_{2}$ influx and leads to a decrease in photosynthesis, limits $\mathrm{CO}_{2}$ fixation, and inhibits plant growth [44]. Stomatal closure also increases the number of electrons that are not used for photosynthesis, and a surplus of electrons generates reactive oxygen species (ROS), which damage the reaction center of photosystem (PS) II [43,45,46]. The Fv/Fm (i.e., the maximum efficiency at which the light absorbed by PS II is used to reduce the primary quinone electron acceptor) decreases when PS II is damaged. However, a recent study of Acer species [47] discussed that only using the Fv/Fm as an indicator of drought stress detection is not suitable. Our results show that significant differences among the clones in $\mathrm{RFv} / \mathrm{Fm}$ reduction only appeared at the end of the drought treatment, suggesting that this situation (when the CWI at 70 CPD was the optimum) might be too severe under natural 
conditions for C. japonica. The response order observed in this study was concordant with the general response of tree species under drought conditions, i.e., the reduction of Ig was very sensitive to drought and, the reduction of the growth rate was moderate, while the Fv/Fm was one of relatively insensitive traits [43,45]. In the present study, by introducing the CWI, the parameter of cumulative stress intensity defined by the CPD, it is suggested that the sensitivity of the measured traits to drought were adequately reflected by our modeling approach using the NLMM.

\subsection{Differences in Clonal Responsivity to Drought Stress}

In this study, our modeling approach allowed us to capture the trait response curves of each clones to drought stress. TE11 seemed to be most insensitive clone among the four tested clones in the responses of the three traits measured in this study (see green lines in Figure 8). Strategies of the drought resistance include drought avoidance and drought tolerance $[43,46,48,49]$. Drought avoidance is based on the ability to maintain the tissue water potential through stomatal closure, root elongation, and high water use efficiency $[43,46,48,49]$. On the other hand, drought tolerance is an ability to endure low tissue water potential by maintaining enzyme activities and osmotic adjustments [43,46,48,49]. Among the four tested clones, TE11 was the most insensitive clone in RIg and, also, the most sustainable clone in GRR against drought stress, suggesting that TE11 might be a superior clone in terms of drought tolerance. There is a possibility of clonal variation in responsivity to drought stress, and therefore, a drought-resistant strategy may differ from clone to clone in C. japonica. In order to get deeper insights, it is necessary to conduct a larger scale drought stress experiment using a larger number of clones in the future.

\section{Conclusions}

As an adaptation to global-scale climate change, tree breeding for drought tolerance is necessary. However, because a traditional approach such as using a gas exchange analyzer is difficult to evaluate the stomatal response of abundant clones to drought stress, mass sample evaluation and the procedures used to accomplish such evaluations are therefore needed in order to increase the efficiency of breeding programs. In this study, we (1) established an evaluation method for estimating the stomatal response against drought stress by measuring leaf temperatures using infrared thermography, (2) evaluated the clonal growth responses and (3) Fv/Fm under conditions of drought stress, and (4) modeled the clonal responses to cumulative drought stress by introducing the CWI. Compared to the traditional approach to evaluate the stomatal response to drought stress using a gas exchange analyzer, the method using an infrared thermography is faster. These methods and findings enabled us to evaluate the clonal stress responses in C. japonica to drought. As a next step, these methods should be applied to large-scale clone materials to promote breeding programs. To accelerate breeding, it is also important to examine the feasibility of genome-wide association studies and genomic selection for assessing drought tolerance in C. japonica.

Supplementary Materials: The following are available online at https:/ /www.mdpi.com/1999-490 7/12/1/55/s1: Figure S1: Changes of the soil water content over the course of the drought experiment. Open and solid circles denote the drought and control treatments, respectively. Black, red, green, and blue correspond to GO1, KA7, TE11, and TS1, respectively. Figure S2: The thermograph taken to obtain the stomatal conductance index $(I g)$. Target: Target individual to measure the $I g$ used in the experiment. Wet reference: The leaves that were sprayed regularly with water to maintain their moisture levels. Dry reference: The leaves that were coated with a mixture of petroleum jelly and liquid paraffin (1:2 by weight). Figure S3: Relationship between the soil water content and soil water potential $\left(\log \Psi_{w}\right)$ of the mixed-culture soil used in the experiment.

Author Contributions: Y.T. and Y.H. conceived and designed the experiments; Y.T. and Y.H. performed the experiments; Y.T., Y.H., and M.M. analyzed the data; Y.T. wrote the manuscript; and Y.T., Y.H., M.M. and M.T. revised the manuscript. All authors have read and agreed to the published version of the manuscript. 
Funding: The present study is part of the project "Development of adaptation techniques to the climate change in the sectors of agriculture, forestry, and fisheries" supported by the Ministry of Agriculture, Forestry and Fisheries, Japan.

Institutional Review Board Statement: Not applicable.

Informed Consent Statement: Not applicable.

Data Availability Statement: The data presented in this study are available on request from the corresponding author.

Acknowledgments: We are grateful to Hiroshi Hoshi (FTBC, FFPRI) for his well-done coordination of the research project.

Conflicts of Interest: The authors declare that the research was conducted in the absence of any commercial or financial relationships that could be construed as a potential conflict of interests.

\section{References}

1. IPCC. Climate Change 2013: The Physical Science Basis: Contribution of Working Group I to the Fifth Assessment Report of the Intergovernmental Panel on Climate Change; Stocker, T.F., Qin, D., Plattner, G.-K., Tignor, M., Allen, S.K., Boschung, J., Nauels, A., Xia, Y., Bex, V., Midgley, P.M., Eds.; Cambridge University Press: Cambridge, UK; New York, NY, USA, 2013.

2. Japan Meteorological Agency. Climate Change Monitoring Report 2017; Japan Meteorological Agency: Tokyo, Japan, 2018.

3. Van Mantgem, P.J.; Stephenson, N.L.; Byrne, J.C.; Daniels, L.D.; Franklin, J.F.; Fulé, P.Z.; Harmon, M.E.; Larson, A.J.; Smith, J.M.; Taylor, A.H.; et al. Widespread increase of tree mortality rates in the western united states. Science 2009, 323, 521-524. [CrossRef] [PubMed]

4. Allen, C.D.; Macalady, A.K.; Chenchouni, H.; Bachelet, D.; McDowell, N.; Vennetier, M.; Kitzberger, T.; Rigling, A.; Breshears, D.D.; Hogg, E.H.T.; et al. A global overview of drought and heat-induced tree mortality reveals emerging climate change risks for forests. For. Ecol. Manag. 2010, 259, 660-684. [CrossRef]

5. Hamanishi, E.T.; Campbell, M.M. Genome-wide responses to drought in forest trees. Forestry 2011, 84, 273-283. [CrossRef]

6. Cortés, A.J.; Restrepo-Montoya, M.; Bedoya-Canas, L.E. Modern strategies to assess and breed forest tree adaptation to changing climate. Front. Plant Sci. 2020, 11, 583323. [CrossRef]

7. Alcaide, F.; Solla, A.; Mattioni, C.; Castellana, S.; Martín, M.Á. Adaptive diversity and drought tolerance in Castanea sativa assessed through EST-SSR genic markers. Forestry 2019, 92, 287-296. [CrossRef]

8. Kumar, A.; Dixit, S.; Ram, T.; Yadaw, R.B.; Mishra, K.K.; Mandal, N.P. Breeding high-yielding drought-tolerant rice: Genetic variations and conventional and molecular approaches. J. Exp. Bot. 2014, 65, 6265-6278. [CrossRef]

9. Mwadzingeni, L.; Shimelis, H.; Tesfay, S.; Tsilo, T.J. Screening of bread wheat genotypes for drought tolerance using phenotypic and prolin analysis. Front. Plant. Sci. 2016, 7, 1276. [CrossRef]

10. Yan, C.; Song, S.; Wang, W.; Wang, C.; Li, H.; Wang, F.; Li, S.; Sun, X. Screening diverse soybean genotypes for drought tolerance by membership function value based on multiple traits and drought-tolerant coefficient of yield. BMC Plant Biol. 2020, $20,321$. [CrossRef]

11. Gasparm, M.J.; Velasco, T.; Feito, I.; Alía, R.; Majada, J. Genetic variation of drought tolerance in Pinus pinaster at three hierarchical levels: A comparison of induced osmotic stress and field testing. PLoS ONE 2013, 8, e79094.

12. Pita, P.; Cañas, I.; Soria, F.; Ruiz, F.; Toval, G. Use of physiological traits in tree breeding for improved yield in drought-prone environments. The case of Eucalyptus globulus. Investig. Agrar. Sist. Recur. For. 2005, 14, 383-393. [CrossRef]

13. Ludovisi, R.; Tauro, F.; Salvati, R.; Khoury, S.; Mugnozza, G.S.; Harfouche, A. UAV-based thermal imaging for high-throughput field phenotyping of black poplar response to drought. Front. Plant Sci. 2017, 10, 3389. [CrossRef] [PubMed]

14. Berry, J.A.; Beerling, D.J.; Franks, P.J. Stomata: Key players in the earth system, past and present. Curr. Opin.Plant Biol. 2010, 13, $233-240$. [CrossRef] [PubMed]

15. Nemeskéri, E.; Molnár, K.; Vígh, R.; Nagy, J.; Dobos, A. Relationships between stomatal behavior, spectral traits and water use and productivity of green peas (Pisum sativum L.) in dry seasons. Acta Physiol. Plant. 2015, 37, 1-16. [CrossRef]

16. Pirasteh-Anosheh, H.; Saed-Moucheshi, A.; Pakniyat, H.; Pessarakli, M. Stomatal responses to drought stress. In Water Stress and Crop Plants: A Sustainable Approach, 1st ed.; Ahmad, P., Ed.; John Wiley \& Sons, Ltd.: New York, NY, USA, 2016; Volume 1, pp. $24-40$.

17. Jones, H.G. Use of infrared thermometry for estimation of stomatal conductance as a possible aid to irrigation scheduling. Agri. For. Meteorol. 1999, 95, 139-149. [CrossRef]

18. Maes, W.H.; Achten, W.M.J.; Reubens, B.; Muys, B. Monitoring stomatal conductance of Jatropha curcas seedlings under different levels of water shortage with infrared thermography. Agri. For. Meteorol. 2011, 151, 554-564. [CrossRef]

19. Seidel, H.; Schunk, C.; Matiu, M.; Menzel, A. Diverging drought resistance of Scots pine provenances revealed by infrared thermography. Front. Plant Sci. 2016, 7, 1247. [CrossRef] [PubMed]

20. Yu, M.H.; Ding, G.D.; Gao, G.L.; Zhao, Y.Y.; Yan, L.; Sai, K. Using plant temperature to evaluate the response of stomatal conductance to soil moisture deficit. Forests 2015, 6, 3748-3762. [CrossRef] 
21. Grant, O.M.; Tronina, Ł.; Jones, H.G.; Chaves, M.M. Exploring thermal imaging variables for the detection of stress responses in grapevine under different irrigation regimes. J. Exp. Bot. 2016, 58, 815-825. [CrossRef]

22. Bolhar-Nordenkampf, H.R.; Long, S.P.; Baker, N.R.; Oquist, G.; Schreiber, U.; Lechner, E.G. Chlorophyll fluorescence as a probe of the photosynthetic competence of leaves in the field: A review of current instrumentation. Funct. Ecol. 1989, 3, 497-514. [CrossRef]

23. Krause, G.H. Chlorophyll fluorescence and photosynthesis: The basics. Ann. Rev. Plant Physiol. Plant Mol. Biol. 1991, 42, 313-349. [CrossRef]

24. Baker, N.R. Chlorophyll fluorescence: A probe of photosynthesis in vivo. Ann. Rev. Plant Biol. 2008, 59, 89-113. [CrossRef] [PubMed]

25. Tezara, W.; Mitchell, V.J.; Driscoll, S.D.; Lawlor, D.W. Water stress inhibits plant photosynthesis by decreasing coupling factor and ATP. Nature 1999, 401, 914-917. [CrossRef]

26. Cornic, G. Drought stress inhibits photosynthesis by decreasing stomatal aperture-Not by affecting ATP synthesis. Trends Plant Sci. 2000, 5, 187-188. [CrossRef]

27. Flexas, J.; Medrano, H. Drought-inhibition of photosynthesis in $\mathrm{C}_{3}$ plants: Stomatal and non-stomatal limitations revisited. Ann. Bot. 2002, 89, 183-189. [CrossRef]

28. Lawlor, D.W.; Cornic, G. Photosynthetic carbon assimilation and associated metabolism in relation to water deficits in higher plants. Plant Cell Environ. 2002, 25, 275-294. [CrossRef]

29. Camisón, Á.; Martín, M.Á.; Dorado, F.J.; Moreno, G.; Solla, A. Changes in carbohydrates induced by drought and waterlogging in Castanea sativa. Trees 2020, 34, 579-591. [CrossRef]

30. Woo, N.S.; Dadger, M.R.; Pogson, B.J. A rapid, non-invasive procedure for quantitative assessment of drought survival using chlorophyll fluorescence. Plant Methods 2008, 4, 27. [CrossRef]

31. Navarro-Cerrillo, R.M.; Rodríguez-Vallejo, C.; Silveiro, E.; Hortal, A.; Palacios-Rodriguez, G.; Duque-Lazo, J.; Camarero, J.J. Cumulative drought stress leads to a loss of growth resilience and explains higher mortality in planted than in naturally regenerated Pinus pinaster stands. Forests 2018, 9, 358. [CrossRef]

32. Zhao, A.; Yu, Q.; Feng, L.; Zhang, A.; Pei, T. Evaluating the cumulative and time-lag effects of drought on grassland vegetation: A case study in the Chinese loess plateau. J. Environ. Manag. 2020, 261, 110214. [CrossRef]

33. Vicente-Serrano, S.M.; Beguería, S.; López-Moreno, J.I. A Multiscalar drought index sensitive to global warming: The standardized precipitation evapotranspiration index. J. Clim. 2010, 23, 1696-1718. [CrossRef]

34. Forestry Agency, Ministry of Agriculture, Forestry and Fisheries of Japan. Statistical Handbook of Forest and Forestry 2019; Forestry Agency, Ministry of Agriculture, Forestry and Fisheries of Japan: Tokyo, Japan, 2019. (In Japanese)

35. Hayashi, Y. An Illustrated Book of Useful Trees; Seibundosinkosha: Tokyo, Japan, 1969; 472p. (In Japanese)

36. Nagakura, J.; Shigenaga, H.; Akama, A.; Takahashi, M. Growth and transpiration of Japanese cedar (Cryptomeria japonica) and Hinoki cypress (Chamaecyparis obtusa) seedlings in response to soil water content. Tree Physiol. 2004, 24, 1203-1208. [CrossRef] [PubMed]

37. Bates, D.; Mächler, M.; Bolker, B.M.; Walker, S.C. Fitting Linear Mixed-Effects Models Using lme4. J. Stat. Softw. 2015, 67, 1-51. [CrossRef]

38. R Core Team. R: A Language and Environment for Statistical Computing; R Foundation for Statistical Computing; R Core Team: Vienna, Austria, 2019.

39. Leinonen, I.; Jones, H.G. Combining thermal and visible imagery for estimating canopy temperature and identifying plant stress. J. Exp. Bot. 2004, 55, 1423-1431. [CrossRef] [PubMed]

40. Nanayakkara, B.; Lagane, F.; Hodgkiss, P.; Dibley, M.; Smaill, S.; Riddell, M.; Harrington, J.; Cown, D. Effects of induced drought and tilting on biomass allocation, wood properties, compression wood formation and chemical composition of young Pinus radiata genotypes (clones). Holzforschung 2014, 68, 455-465. [CrossRef]

41. Bigras, F.J. Photosynthetic response of white spruce families to drought stress. New For. 2005, 29, 135-148. [CrossRef]

42. Pei, Z.-M.; Murata, Y.; Benning, G.; Thomine, S.; Klüsener, B.; Allen, G.J.; Grill, E.; Schroeder, J.I. Calcium channels activated by hydrogen peroxide mediate abscisic acid signalling in guard cells. Nature 2000, 406, 731-734. [CrossRef]

43. Aroca, R. Plant Responses to Drought Stress: From Morphological to Molecular Features; Springer: Berlin, Germany, 2012.

44. Peñuelas, J.; Filella, I.; Llusià, J.; Siscart, D.; Piñol, J. Comparative field study of spring and summer leaf gas exchange and photobiology of the mediterranean trees Quercus ilex and Phillyrea latifolia. J. Exp. Bot. 1998, 49, 229-238. [CrossRef]

45. Hsiao, T.C. Plant Responses to Water Stress. Ann Rev. Plant Physiol. 1973, 24, 519-570. [CrossRef]

46. Osakabe, Y.; Osakabe, K.; Shinozaki, K.; Tran, L.-S.P. Response of plants to water stress. Front Plant Sci. 2014, 5, 1-8. [CrossRef]

47. Banks, J.M. Chlorophyll fluorescence as a tool to identify drought stress in Acer genotypes. Eviron. Exp. Bot. 2018, 155, 118-127. [CrossRef]

48. Touchette, B.W.; Iannacone, L.R.; Turner, G.E.; Frank, A.R. Drought tolerance versus drought avoidance: A comparison of plant-water relations in herbaceous wetland plants subjected to water withdrawal and repletion. Wetlands 2007, 3, 656-667. [CrossRef]

49. Moran, E.; Lauder, J.; Musser, C.; Stathos, A.; Shu, M. The genetics of drought tolerance in conifer. New Phytol. 2017, 216, 1038-1048. [CrossRef] [PubMed] 